\title{
Vendor managed inventory in multi level supply chain
}

\author{
Hamid Bani-Asadi ${ }^{\mathbf{a}^{*}}$ and Hamed Jafar Zanjani ${ }^{\mathrm{b}}$
}

${ }^{a}$ Graduate student of Industrial Engineering, Department of Industrial Engineering, Naragh Branch, Islamic Azad University, Iran ${ }^{b}$ Assistant Professor, Department of Industrial Engineering, Naragh Branch, Islamic Azad University, Naragh, Iranniversity, Iran

\begin{tabular}{l}
\hline C H R O N I C L E \\
\hline Article history: \\
Received February 25, 2016 \\
Received in revised format: \\
March 28, 2016 \\
Accepted July 12, 2016 \\
Available online \\
July 152016 \\
\hline Keywords: \\
Supply chain management \\
Vendor management inventory \\
Particle swarm optimization \\
Genetic algorithm
\end{tabular}

\section{A B S T R A C T}

Vendor managed inventory (VMI) is one of the most effective methods for reducing bullwhip effect. This paper presents a mathematical VMI model where there are three levels of central storage, multi distribution centers and various retailors. The problem is formulated as a mixed integer programming by considering uncertainty on different input parameters. To cope with uncertainty, the study uses rectangular fuzzy numbers. We also propose two metaheuristics; namely, genetic algorithm and particle swarm optimization to solve the resulted problems for some large instances. The preliminary results have indicated that genetic algorithm could solve the proposed model faster than particle swarm optimization in terms of CPU time reaching to slightly better objective functions.

(c) 2017 Growing Science Ltd. All rights reserved.

\section{Introduction}

Supply Chain Management (SCM) is an important component to operational efficiency. SCM can be implemented to customer satisfaction and firm success (Chopra \& Meindl, 2007; Pasandideh et al., 2011). Since SCM plays essential role within organizations, employers look for employees with an abundance of SCM skills and knowledge. Supply chain management is essential to business operations and success for many reasons. Presently, the world is one big supply chain and SCM touches major issues, including the quick growth of multinational corporations and strategic partnerships; global expansion and sourcing; fluctuating gas prices and environmental concerns, each of these issues substantially influences on firm strategy. Vendor managed inventory (VMI), as part of SCM, has become an interesting topic among researchers. VMI is an integrated method for retailer-vendor coordination, according to which the vendor decides on the suitable inventory levels within bounds that are agreed based on an agreement between vendor and retailers. In this contract, the vendor normally pays a penalty for items exceeding these bounds (Darwish \& Odah, 2010).

\footnotetext{
* Corresponding author.

E-mail address: hamid.baniasadi@gmail.com (H. Bani-Asadi) 
Almehdawe and Mantin (2010) considered a Stackelberg game VMI framework under two scenarios where in the first one manufacturer is the leader and in the second one, the retailers act as the dominant player of the supply chain and provided some insights on both cases. Arora et al. (2010) proposed a quaternary policy system for integrated logistics and inventory perspective of the supply chain where VMI system was implemented for updating the inventory of the retailers. Kim and Park (2010) analyzed and confirmed the dynamic coordination of key decision variables by the supply chain partners in the VMI relationship. Cárdenas-Barrón et al. (2012) presented a heuristics to solve the VMI system with multi-product and multi-constraint based on economic order quantity with backorders by taking into account two classical backorders costs of linear and fixed. Chen et al. (2010) considered a coordinating of a vertically separated distribution system under VMI and consignment arrangements. They formulated the profit-maximization problem and carried out equilibrium analysis under cooperative and non-cooperative settings. Hariga et al. (2013) considered a supply chain composed of a single vendor and multiple retailers operating under a VMI contract that specifies limits on retailers' stock levels. Kristianto et al. (2012) proposed an adaptive fuzzy control application to support a VMI. The methodology implemented fuzzy control to create an adaptive smoothing constant in the forecast method, production and delivery plan to remove, for instance, the rationing and gaming or the Houlihan effect and the order batching effect or the Bullwhip effect. They reported that the adaptive fuzzy VMI control could surpass fuzzy VMI control and traditional VMI in terms of mitigating the Bullwhip effect.

Huang et al. (2010) dealt with "the order-processing cost reduction and permissible delay in payments problem in the single-vendor single-buyer integrated inventory model". They considered that the orderprocessing cost could be reduced, which differs with the reduction in the order-processing time length. Nachiappan and Jawahar (2007) proposed a genetic algorithm for optimal operating parameters of VMI system in a two-echelon supply chain. Nia et al. (2014) developed a fuzzy VMI of multi-item EOQ model under shortage and solved the resulted model using an ant colony optimization algorithm. According to Sadeghi et al. (2013), the VMI is a common policy in SCM to reduce bullwhip effects. There are various applications of VMI proposed in the literature but limited works focused on the multi-vendor multi-retailer single-warehouse (MV-MR-SW) case. Sadeghi et al. (2013) developed a constrained MV-MR-SW supply chain, in which both the space and the annual number of orders of the central warehouse were limited. They formulated the model and used particle swarm optimization (PSO) to determine an approximate optimum solution of the problem. Sadeghi et al. (2014), in other work, proposed a hybrid VMI and redundancy allocation optimization problem in SCM. Wong et al. (2009) explained how a sales rebate contract could help reach supply chain coordination. They proposed a model in the context of a two-echelon supply chain with a single supplier serving multiple retailers in VMI partnership. The proposed model demonstrated that the supplier could gain more profit with competing retailers than without as competition among the retailers lowers the prices. Xiao and $\mathrm{Xu}$ (2013) proposed a method for coordinating price and service level decisions for a supply chain with deteriorating item under VMI system. Yao et al. (2007) developed an analytical model, which explores how essential supply chain parameters could influence on the cost savings to be realized from collaborative initiatives such as VMI. They reported that benefits, in the form of inventory cost reductions, could be made from integration depending on the ratio of the order costs of the supplier to the buyer and the ratio of the carrying charges of the supplier to the buyer.

\section{The proposed study}

In this study, it is assumed that all suppliers provide the same goods from a central warehouse, which means we may add a fixed cost to the objective function. The study presents a mathematical VMI model where there are three levels of central storage, multi distribution centers and various retailors.

\section{Indices}

$i=1, \ldots, I \quad$ Index for suppliers

$j=1, \ldots, J \quad$ Index for retailors 
$k=1, \ldots, K \quad$ Products

$m=1, \ldots, M \quad$ Discounts for purchasing products in higher volumes

$t=1, \ldots, T \quad$ Planning horizon

\section{Parameters}

$\widetilde{L_{l k}}$ Lower limit for the amount of order by supplier $i$ for product $k$ during the time $t$

$\widetilde{U_{l k}}$ Upper limit for the amount of order by supplier $i$ for product $k$ during the time $t$

TJkt Lower limit for the amount of order by retailor $j$ for product $k$ during the time $t$

$\widetilde{S_{J k}} \quad$ Upper limit for the amount of order by retailor $j$ for product $k$ during the time $t$

$D_{\mathrm{ikt}} \quad$ Demand for supplier $i$ for product $k$ during the time $t$

$\mathrm{d}_{\mathrm{jkt}} \quad$ Demand for retailor $j$ for product $k$ during the time $t$

$\mathrm{A}_{\mathrm{ikt}} \quad$ Fixed cost for product $k$ by supplier $i$ in time $t$

$a_{\mathrm{jkt}} \quad$ Fixed cost for product $k$ by retailor $j$ in time $t$

$\mathrm{h}_{\mathrm{ikt}} \quad$ Holding cost for product $k$ by supplier $i$ in time $t$

$\pi_{1} \quad$ The fixed cost of backorder

$\pi_{2} \quad$ The variable cost of backorder

$f_{\text {ik }} \quad$ Total space occupied by product type $k$ for supplier $i$

$\mathrm{F} \quad$ Total available space

$C_{\text {ikt }} \quad$ Capacity of supplier $i$ for product $k$ during the time $t$

$\mathrm{P}_{\mathrm{ikmt}} \quad$ Percentage of remanufacturable of product $k$ purchased from supplier $i$ at discount price level $m$ and time $t$

$q_{\mathrm{ikmt}} \quad$ Percentage of unremanufacturable of product $k$ ordered from supplier $i$ at discount price level $m$ and time $t$

$V_{\text {ikmt }} \quad$ Price of remanufacturable product $k$ ordered from supplier $i$ at discount price level $m$ and time $t$

$r_{\mathrm{ikmt}} \quad$ Price of product $k$ ordered from supplier $i$ at discount price level $m$ and time $t$

$M_{\mathrm{ikt}} \quad$ The upper limit of the number of pallets to order product $k$ by supplier $i$ during the time $t$

G Capacity of pallets

\section{Variables}

$\mathrm{x}_{\mathrm{ikmt}} \quad$ The number of products $k$ ordered from supplier $i$ at discount price level $m$ and time $t$

$y_{i k m t} \quad$ A binary variable, which is one if $x_{i k m t}$ is greater than zero and zero, otherwise

$\mathrm{Q}_{\mathrm{ikt}} \quad$ The amount of order size by supplier $i$ for product $k$ at time $t$

$\mathrm{q}_{\mathrm{jkt}} \quad$ The amount of order size by retailor $j$ for product $k$ at time $t$

$z_{i k t} \quad$ A binary variable, which is one if $q_{i k t}$ is greater than zero and zero, otherwise

$b_{\mathrm{ikt}} \quad$ The maximum backordered items by supplier $i$ for product $k$ at time $t$

The proposed study of this paper uses fuzzy numbers to handle uncertainty as shown in Fig. 1.

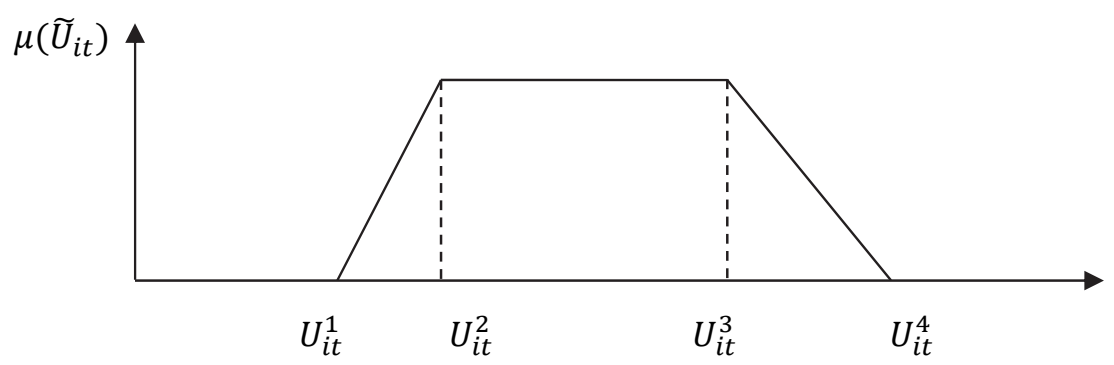

Fig. 1. A rectangular fuzzy number 
In order to defuzzify the fuzzy numbers we use the following

$$
(\widetilde{U})=\frac{U^{1}+U^{2}+U^{3}+U^{4}}{4}-\sigma\left(\frac{U^{3}-U^{2}}{4}+\frac{U^{4}-U^{1}}{2}\right),
$$

where $\sigma=0.01$ or $\sigma=0.05$. The proposed study can be formulated as follows,

$$
\begin{array}{lc}
\sum_{\mathrm{i}=1}^{\mathrm{I}} \sum_{\mathrm{k}=1}^{\mathrm{K}} \mathrm{f}_{\mathrm{ik}}\left(\mathrm{Q}_{\mathrm{ikt}}-\mathrm{b}_{\mathrm{ikt}}\right) \leq \mathrm{F} & \forall \mathrm{t} \\
\tilde{L}_{\mathrm{ikt}} \leq \mathrm{Q}_{\mathrm{ikt}} \leq \widetilde{\mathrm{U}}_{\mathrm{ikt}} & \forall_{\mathrm{i}, \mathrm{k}, \mathrm{t}} \\
\widetilde{T}_{\mathrm{jkt}} \leq \mathrm{q}_{\mathrm{jkt}} \leq \widetilde{\mathrm{S}}_{\mathrm{jkt}} & \forall_{\mathrm{j}, \mathrm{k}, \mathrm{t}} \\
Q_{\mathrm{ikt}}=\mathrm{G} \cdot \mathrm{N}_{\mathrm{ikt}} & \forall_{\mathrm{i}, \mathrm{k}, \mathrm{t}} \\
N_{\mathrm{ikt}} \leq \mathrm{M}_{\mathrm{ikt}} & \forall_{\mathrm{i}, \mathrm{k}, \mathrm{t}} \\
Q_{\mathrm{ikt}} \geq \mathrm{b}_{\mathrm{ikt}} & \forall_{\mathrm{i}, \mathrm{k}, \mathrm{t}} \\
x_{\mathrm{ikmt}} \leq \mathrm{C}_{\mathrm{ikmt}} \cdot \mathrm{y}_{\mathrm{ikmt}} & \forall_{\mathrm{i}, \mathrm{k}, \mathrm{t}} \\
\sum_{m=1}^{\mathrm{M}} \mathrm{y}_{\mathrm{ikmt}}=\mathrm{Z}_{\mathrm{ikt}} &
\end{array}
$$

Eq. (1) specifies the amount of spaces available for supplier. Eq. (2) and Eq. (3) determine lower and upper bounds for $Q_{\mathrm{ikt}}$ and $\mathrm{q}_{\mathrm{jkt}}$, respectively. According to Eq. (4), $Q_{\mathrm{ikt}}$ is determined by an interger number $\mathrm{N}_{\mathrm{ikt}}$ with the maximum amount of $\mathrm{M}_{\mathrm{ikt}}$. According to Eq. (6), order should be at least more than shortage. According to Eq. (7), when $y_{\mathrm{ikmt}}=1 x_{\mathrm{ikmt}}$ can receive a value up to maximum capacity. Eq. (8) insures that order will lead to purchase. The resulted model is a mixed integer programming and can be solved for small size instances using a direct solver and for large scale problems, we may use metaheuristics. The proposed method of this paper uses genetic algorithm (GA) and particle swarm optimization (PSO).

\subsection{Genetic algorithm}

GA has been recognized as the most well-known metaheuristic algorithm in the world. Holland (1992) is believed to be the founder of GA and it has been widely implemented for various classes of problems. GA is considered as a metaheuristic search, which mimics the process of natural selection. The processed is routinely implemented to build useful solutions to optimization and search problems. It is associated with the bigger class of evolutionary algorithms (EA), which create solutions to optimization problems based on techniques inspired by natural evolution, including inheritance, mutation, selection, and crossover. The chromosome of the genetic algorithm consists of four parts. The first part is associated with the amount of product purchased by each supplier $(X)$. The second part shows the intervals of discount for purchasing products $(Y)$, the third part demonstrates the lot size $(\mathrm{Q})$ and finally, the last part is associated with lot size assigned to each retailor. Chromosomes one, two and four contain real numbers while the third chromosome contains binary numbers. For crossover, we use the following,

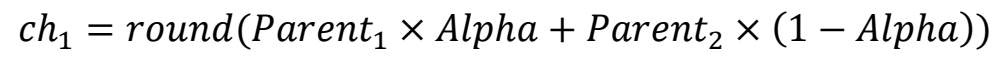




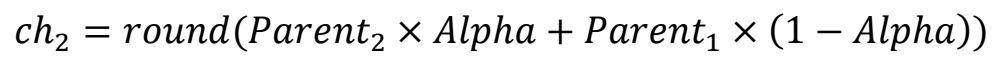

where new generations $\left(c h_{1}\right)$ and $\left(c h_{2}\right)$ are generated by Parent Pand $_{1}$ Parent ${ }_{2}$, respectively and Alpha is an arbitrary number, which is given 0.4 in this paper. Fig. 1 shows details of crossover operations.

Paret $_{1} \times$ Alpha

\begin{tabular}{|c|c|c|}
\hline 20 & 0 & 30 \\
\hline 50 & 30 & 0 \\
\hline 0 & 0 & 40 \\
\hline
\end{tabular}

Paret $_{1} \times(1-$ Alpha $)$

\begin{tabular}{|c|c|c|}
\hline 20 & 0 & 30 \\
\hline 50 & 30 & 0 \\
\hline 0 & 0 & 40 \\
\hline
\end{tabular}

Paret $_{2} \times(1-$ Alpha $)$

\begin{tabular}{|c|c|c|}
\hline 0 & 50 & 60 \\
\hline 30 & 40 & 20 \\
\hline 40 & 30 & 0 \\
\hline \multicolumn{3}{|c|}{ Paret $\times$ Alpha } \\
\hline
\end{tabular}

\begin{tabular}{|c|c|c|}
\hline 0 & 50 & 60 \\
\hline 30 & 40 & 20 \\
\hline 40 & 30 & 0 \\
\hline
\end{tabular}

First child

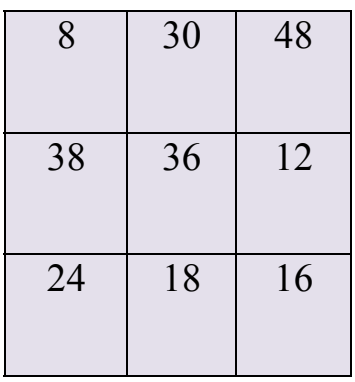

Second child

\begin{tabular}{|c|c|c|}
\hline 12 & 20 & 42 \\
\hline 42 & 34 & 8 \\
\hline 16 & 12 & 24 \\
\hline
\end{tabular}

Fig. 1. Crossover operations

The mutation also is executed by randomly changing of the components of the chromosome as shown in Fig. 2 as follows,

Before

\begin{tabular}{|c|c|c|}
\hline 0 & 50 & 60 \\
\hline 30 & 40 & 20 \\
\hline 40 & 30 & 0 \\
\hline
\end{tabular}

After

\begin{tabular}{|c|c|c|}
\hline 0 & 50 & 60 \\
\hline 30 & 40 & 20 \\
\hline 40 & 24 & 0 \\
\hline
\end{tabular}

Fig. 2. The procedure of mutations

Stop condition for the proposed GA is set to the maximum number of iterations and the selection process is based on roulette wheel algorithm.

\subsection{Particle swarm optimization}

Particle swarm optimization (PSO) is an evolutionary method for minimization of functions designed 
based on social behavior of birds by Kennedy (2010). In this method, a group of particles, as the variables of the problem, are scattered in the search environment. More specifically, some particles maintain better positions than others do. Thus, based on aggregative particles' behavior, other particles have to attempt to raise their position to the prior particles' positions. The proposed PSO uses the following notations,

$$
\begin{array}{ll}
t, t=1, \ldots, T & \text { Index for repetition } \\
i, i=1, \ldots, I & \text { Index for particles } \\
d, d=1, \ldots, D & \text { Index for dimensions } \\
u & \text { Uniform distribution number }[0,1] \\
p_{i d} & \text { Position of pbest particle } i \text { in dimension } d \\
p_{g d} & \text { Position of gbest in dimension } d \\
c_{p} & \text { Acceleration factor of pbest } \\
c_{g} & \text { Acceleration factor of } g b e s t \\
X^{m i n} & \text { The minimum value of position } \\
X^{\text {max }} & \text { The maximum value of position } \\
w & \text { Static weight } \\
v_{i d}(t) & \text { Velocity of } i t h \text { particle in dimension } d \text { and repetition } t \\
x_{i d}(t) & \text { Position of } i^{t h} \text { particle in dimension } d \text { and repetition } t \\
X_{i} & \text { Vector of position }\left[\mathrm{x}_{\mathrm{i} 1}, \mathrm{x}_{\mathrm{i} 2}, \ldots, \mathrm{x}_{\mathrm{iD}}\right] \\
\mathrm{V}_{\mathrm{i}} & \text { Vector of velocity }\left[\mathrm{v}_{\mathrm{i} 1}, \mathrm{v}_{\mathrm{i} 2}, \ldots, \mathrm{v}_{\mathrm{iD}}\right] \\
\mathrm{p}_{\mathrm{i}} & \text { Vector of position of pbest }\left[\mathrm{p}_{\mathrm{i} 1}, \mathrm{p}_{\mathrm{i} 2}, \ldots, \mathrm{p}_{\mathrm{iD}}\right] \\
\mathrm{p}_{\mathrm{g}} & \text { Vector of position of gbest }\left[\mathrm{p}_{\mathrm{g} 1}, \mathrm{p}_{\mathrm{g} 2}, \ldots, \mathrm{p}_{\mathrm{gD}}\right] \\
\mathrm{z}\left(\mathrm{x}_{\mathrm{i}}\right) & \text { The competence of } \mathrm{X}_{\mathrm{i}}
\end{array}
$$

The proposed study uses the following to adjust the speed and the position for each particle.

$$
\begin{aligned}
& v(t+1)=w v(t)+c_{p} u\left(x(t)-x_{\text {pbest }}\right)+c_{g} u\left(x(t)-x_{\text {gbest }}\right), \\
& x(t+1)=x(t)+v(t+1) .
\end{aligned}
$$

PSO Algorithm

Step 1. Initial values

Generate $\mathrm{X}_{\mathrm{i}}$ in the interval $\left[X^{\min }, X^{\max }\right], i=1, \ldots, I$

Set $P_{g}=X_{1}, P_{i}=X_{i}, V_{i}=0$

Step 2. Obtain $Z\left(X_{i}\right)$ for $\mathrm{i}=1, \ldots$, I

Step 3. Update pbest, if $\mathrm{z}\left(\mathrm{x}_{\mathrm{i}}\right)<\mathrm{z}\left(\mathrm{p}_{\mathrm{i}}\right)$ then $\mathrm{P}_{\mathrm{i}}=\mathrm{X}_{\mathrm{i}}, i=1, \ldots, I$ 
Step 4. Update gbest, if $\mathrm{z}\left(\mathrm{p}_{\mathrm{i}}\right)<\mathrm{z}\left(\mathrm{p}_{\mathrm{i}}\right)$ then $\mathrm{P}_{\mathrm{i}}=\mathrm{P}_{\mathrm{i}}, i=1, \ldots, I$

Step 5. Update velocity and position of each particle according to Eq. (5) and Eq. (6)

$$
\begin{aligned}
& \text { If } \mathrm{x}_{\mathrm{id}}(\mathrm{t}+1)>\mathrm{X}^{\mathrm{max}} \text { then } \mathrm{x}_{\mathrm{id}}(\mathrm{t}+1)=\mathrm{X}^{\mathrm{max}} \text { and } \mathrm{v}_{\mathrm{id}}(\mathrm{t}+1)=0 \\
& \text { If } \mathrm{x}_{\mathrm{id}}(\mathrm{t}+1)<\mathrm{X}^{\mathrm{min}} \text { then } \mathrm{x}_{\mathrm{id}}(\mathrm{t}+1)=\mathrm{X}^{\text {min }} \text { and } \mathrm{v}_{\mathrm{id}}(\mathrm{t}+1)=0
\end{aligned}
$$

Step 6. If $\mathrm{t}=\mathrm{T}$ Stop, otherwise $t=t+1$ go to Step 2.

\section{The results}

In this section, we study the performance of the proposed method using some randomly generated test data. Table 1 demonstrates the numbers used for the proposed study.

\section{Table 1}

The summary of test data

\begin{tabular}{lccccc}
\hline Prob. & Distribution centers & \# of products & \# of retailors & Discount levels & \# of periods \\
\hline 1 & 2 & 3 & 4 & 3 & 2 \\
2 & 2 & 3 & 5 & 3 & 4 \\
3 & 3 & 4 & 7 & 3 & 4 \\
4 & 5 & 5 & 9 & 3 & 6 \\
5 & 8 & 5 & 11 & 3 & 6 \\
6 & 8 & 6 & 13 & 3 & 10 \\
7 & 15 & 6 & 20 & 3 & 12 \\
8 & 20 & 7 & 30 & 3 & 12 \\
\hline
\end{tabular}

In addition, the following parameters are used

\begin{tabular}{cccc}
\hline Variable & $\mathrm{U}(a, b)$ & Variable & $U(a, b)$ \\
\hline$L_{i k t}$ & $\mathrm{U}(0,30)$ & $H_{i k t}$ & $\mathrm{U}(2,10)$ \\
$U_{i k t}$ & $\mathrm{U}(120,250)$ & $F_{i k}$ & $\mathrm{U}(5,15)$ \\
$T_{j k t}$ & $\mathrm{U}(0,50)$ & $M_{i k t}$ & $\mathrm{U}(30,100)$ \\
$S_{j k t}$ & $\mathrm{U}(60,250)$ & $P_{i k t}$ & $\mathrm{U}(0.01, .1)$ \\
$A_{i k t}$ & $\mathrm{U}(10,20)$ & $q_{i k t}$ & $\mathrm{U}(0.01, .1)$ \\
$a_{j k t}$ & $\mathrm{U}(12,20)$ & $C_{i k t}$ & $\mathrm{U}(100, .300)$ \\
$D_{i k t}$ & $\mathrm{U}(50,150)$ & $r_{i k t}$ & $\mathrm{U}(10, .40)$ \\
$d_{j k t}$ & $\mathrm{U}(50,100)$ & $v_{i k t}$ & $\mathrm{U}(5, .15)$ \\
$b_{i k t}$ & $\mathrm{U}(10,20)$ & & \\
\hline
\end{tabular}

The parameters in GA method are set according to Table 2 as follows.

\section{Table 2}

The summary of parameters set for GA method

\begin{tabular}{lcccccc}
\hline Problem size & repeat & $\begin{array}{c}\text { Initial } \\
\text { population }\end{array}$ & Alpha & Mutilation rate & $\begin{array}{c}\text { Best } \\
\text { neighborhood }\end{array}$ & $\begin{array}{c}\text { Rate of best } \\
\text { particle }\end{array}$ \\
\hline Small $(1,2,3)$ & 500 & 30 & 0.6 & 0.4 & 2 & 2 \\
Medium $(4,5,6)$ & 750 & 40 & 0.7 & 0.3 & 2 & 2 \\
Large $(7,8,9)$ & 750 & 40 & 0.6 & 0.4 & 2 & 2 \\
\hline
\end{tabular}


The problem has been coded on a computer Intel ${ }^{\circledR}$ Core $^{\text {TM }} 2$ Duo CPU with $2.0 \mathrm{GHz}$ and $2.00 \mathrm{~Gb}$ RAM with Microsoft Windows 7 Ultimate. Table 3 presents the results of optimal solutions using direct implementation of Lingo software package. As we can observe from the results of Table 3, the relative gaps calculated by (metaheuristic-optimal)/optimal are given in the last column of the table. As we can observe both GA and PSO have reached near-optimal solutions in significantly lower amount of time. We have solved the problem for larger sizes and Table 4 shows the results.

Table 3

The results of the implementation of a mixed integer programming, GA and PSO

\begin{tabular}{lccccccccc}
\hline & \multicolumn{3}{c}{ Lingo } & \multicolumn{3}{c}{ GA } & \multicolumn{3}{c}{ PSO } \\
\hline Prob. & $F$ & Obj. fun. & CPU time & Obj. & CPU time & Gap & Obj. fun. & CPU time & Gap \\
\hline 1 & 950 & 4379 & 1839 & 4396 & 30 & 0.003 & 4413 & 71 & 0.007 \\
1 & 1200 & 4045 & 1665 & 4079 & 24 & 0.008 & 4091 & 66 & 0.011 \\
2 & 1400 & 9425.3 & 6816 & 9472 & 42 & 0.005 & 9613 & 81 & 0.02 \\
2 & 1100 & 9106.5 & 6548 & 9142 & 39 & 0.004 & 9297 & 76 & 0.021 \\
3 & 1700 & 14594 & 18114 & 14754 & 56 & 0.011 & 14856 & 91 & 0.018 \\
3 & 2000 & 13594 & 18302 & 13797 & 53 & 0.015 & 13906 & 85 & 0.023 \\
\hline Aver & & & & & 0.077 & & & 0.0167 \\
\hline
\end{tabular}

Table 4

The results of the implementation of GA and PSO for large scale problems

\begin{tabular}{cccccc}
\hline & & \multicolumn{2}{c}{ GA } & \multicolumn{2}{c}{ PSO } \\
\cline { 2 - 6 } Prob. & F & Obj. func. & CPU (Sec) & Object. Func. & CPU (Sec) \\
\hline 4 & 2100 & 18781 & 75 & 18987 & 112 \\
4 & 2500 & 18357 & 66 & 18724 & 110 \\
5 & 2100 & 23654 & 94 & 23961 & 139 \\
\hline 5 & 2500 & 23006 & 86 & 23190 & 128 \\
6 & 2700 & 30895 & 114 & 31821 & 159 \\
6 & 3000 & 30646 & 105 & 31871 & 150 \\
7 & 3200 & 38856 & 143 & 40215 & 178 \\
7 & 3500 & 38012 & 137 & 38392 & 174 \\
8 & 3900 & 46839 & 176 & 47775 & 226 \\
\hline 8 & 4200 & 45987 & 181 & 48194 & 217 \\
9 & 4700 & 57024 & 213 & 59190 & 246 \\
\hline 9 & 5000 & 56823 & 201 & 59266 & 241 \\
\hline
\end{tabular}

The results of Table 4 show that GA outperforms PSO in terms of CPU and objective functions.

\section{Conclusion}

In this article, we have developed a mathematical model for a supply chain system with three levels including a supplier, a distributer and a retailor by minimizing total cost including the ordering cost, and backorder. The resulted model has been formulated as a mixed integer programming and using two metaheuristics; namely genetic algorithm and particle swarm optimization, the problem has been solved for optimality. The preliminary results have indicated that both GA and PSO, have been able to solve the problem for large instances, although, GA has appeared to perform better than PSO in terms of CPU time and objective function values. As a future study, it is possible to build a robust model using recent advances of optimization techniques and we leave it as an opportunity for interested readers as future research. 


\section{Acknowledgement}

The authors would like to thank the anonymous referees for constructive comments on earlier version of this paper.

\section{References}

Almehdawe, E., \& Mantin, B. (2010). Vendor managed inventory with a capacitated manufacturer and multiple retailers: Retailer versus manufacturer leadership. International Journal of Production Economics, 128(1), 292-302.

Arora, V., Chan, F. T., \& Tiwari, M. K. (2010). An integrated approach for logistic and vendor managed inventory in supply chain. Expert Systems with Applications, 37(1), 39-44.

Cárdenas-Barrón, L. E., Treviño-Garza, G., \& Wee, H. M. (2012). A simple and better algorithm to solve the vendor managed inventory control system of multi-product multi-constraint economic order quantity model. Expert Systems with Applications, 39(3), 3888-3895.

Chen, J. M., Lin, I. C., \& Cheng, H. L. (2010). Channel coordination under consignment and vendormanaged inventory in a distribution system.Transportation Research Part E: Logistics and Transportation Review, 46(6), 831-843.

Chopra, S., \& Meindl, P. (2007). Supply chain management. Strategy, planning \& operation. In Das Summa Summarum des Management (pp. 265-275). Gabler.

Darwish, M. A., \& Odah, O. M. (2010). Vendor managed inventory model for single-vendor multiretailer supply chains. European Journal of Operational Research, 204(3), 473-484.

Hariga, M., Gumus, M., Daghfous, A., \& Goyal, S. K. (2013). A vendor managed inventory model under contractual storage agreement. Computers \& Operations Research, 40(8), 2138-2144.

Holland, J., (1992). Adaptation in natural and artificial systems: MIT Press. Cambridge, MA.

Huang, C. K., Tsai, D. M., Wu, J. C., \& Chung, K. J. (2010). An optimal integrated vendor-buyer inventory policy under conditions of order-processing time reduction and permissible delay in payments. International Journal of Production Economics, 128(1), 445-451.

Kennedy, J. (2010). Particle swarm optimization. In Encyclopedia of Machine Learning (pp. 760-766). Springer US.

Kim, B., \& Park, C. (2010). Coordinating decisions by supply chain partners in a vendor-managed inventory relationship. Journal of Manufacturing Systems, 29(2), 71-80.

Kristianto, Y., Helo, P., Jiao, J. R., \& Sandhu, M. (2012). Adaptive fuzzy vendor managed inventory control for mitigating the Bullwhip effect in supply chains. European Journal of Operational Research, 216(2), 346-355.

Nachiappan, S. P., \& Jawahar, N. (2007). A genetic algorithm for optimal operating parameters of VMI system in a two-echelon supply chain.European Journal of Operational Research, 182(3), 14331452.

Nia, A. R., Far, M. H., \& Niaki, S. T. A. (2014). A fuzzy vendor managed inventory of multi-item economic order quantity model under shortage: An ant colony optimization algorithm. International Journal of Production Economics, 155, 259-271.

Pasandideh, S. H. R., Niaki, S. T. A., \& Nia, A. R. (2011). A genetic algorithm for vendor managed inventory control system of multi-product multi-constraint economic order quantity model. Expert Systems with Applications, 38(3), 2708-2716.

Sadeghi, J., Mousavi, S. M., Niaki, S. T. A., \& Sadeghi, S. (2013). Optimizing a multi-vendor multiretailer vendor managed inventory problem: Two tuned meta-heuristic algorithms. KnowledgeBased Systems, 50, 159-170.

Sadeghi, J., Sadeghi, S., \& Niaki, S. T. A. (2014). A hybrid vendor managed inventory and redundancy allocation optimization problem in supply chain management: An NSGA-II with tuned parameters. Computers \& Operations Research, 41, 53-64.

Wong, W. K., Qi, J., \& Leung, S. Y. S. (2009). Coordinating supply chains with sales rebate contracts and vendor-managed inventory. International Journal of Production Economics, 120(1), 151-161.

Xiao, T., \& Xu, T. (2013). Coordinating price and service level decisions for a supply chain with 
deteriorating item under vendor managed inventory.International Journal of Production Economics, 145(2), 743-752.

Yao, Y., Evers, P. T., \& Dresner, M. E. (2007). Supply chain integration in vendor-managed inventory. Decision support systems, 43(2), 663-674.

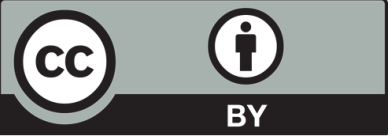

(C) 2016 by the authors; licensee Growing Science, Canada. This is an open access article distributed under the terms and conditions of the Creative Commons Attribution (CC-BY) license (http://creativecommons.org/licenses/by/4.0/). 